\title{
Universities push for creation of advanced energy research centres
}

US universities are pressing the Carter administration to help set up a number of university-based advanced energy research centres, concentrating on areas of interdisciplinary research that currently fall between the mission-oriented R\&D programmes of the Department of Energy and its basic research commitments.

In his budget request to Congress for the fiscal year 1981, the President has suggested that $\$ 3$ million be allocated to the department to support the initiation of such centres, an idea formally suggested only last October by Dr David Saxon, president of the University of California.

The universities hope that the administration can be persuaded to contribute more than $\$ 150$ million over the next three years both to establishing 15 such centres, and to provide a national support programme of grants, traineeships and fellowships.

Administration officials are approaching the scheme cautiously, however, pointing out that the value of such centres should be judged on their scientific merits - and sceptical of any demands to institutionalise university research efforts.

The decision to provide the initial funding for a number of centres, albeit at a much lower level than the $\$ 15$ million Dr Saxon had suggested, reflects a growing desire within the Department of Energy to emphasise the potential role of universities in carrying out what is referred to as "goaloriented basic research".

In the 1981 budget request for the DoE Office of Energy Research, for example, funding for university-based energy research is scheduled to increase by $22 \%$, a real growth of about $12 \%$; in particular, "university research support", which includes the new interdisciplinary centres, would more than double, from $\$ 7.1$ million to $\$ 14.3$ million.

The specific proposals made by $\mathrm{Dr}$ Saxon were backed up by a report which he commissioned last August from the Association of American Universities. Prepared by a committee under Dr Jack Hollander, associate director of the University of California's Lawrence Berkeley Laboratory, the report was on Dr Saxon's desk within five weeks, and passed to Washington shortly after.

The main foci of the report are claimed gaps in the department's research strategy - and the way that universities might help to fill them. In particular, the report claims that the heavy emphasis within major R\&D programmes on short-term technology development "inhibits the pursuit of goaloriented basic research and the interaction of university researchers with the department".

In general it says that "much goaloriented basic research tends to be considered too basic by the DoE missionoriented programmes, and too applied by the DoE/OER basic science programmes". Examples of such research gaps, it suggests, can be found in fields such as synthetic fuels and nuclear waste disposal.

In transmitting the report to Dr Frank Press, director of the Office of Energy Research, and Dr John Deutch, undersecretary for energy, Dr Saxon spoke of the "urgent need for very substantial improvement and expansion" in the department's research strategy.

Building on the AAU report's conclusions, Dr Saxon suggested that the department agree to intiate support for five centres a year over the next three years, each centre receiving $\$ 2$ million for "core support" and $\$ 1$ million for scientific equipment.

Centres would be selected on the basis of a national competition. Each would build a "coordinated, coherent research programme around a central theme or subject"; styles would vary from new interdisciplinary laboratories in technical fields (such as the Materials Research Laboratories established by the Department of Defense) to interdisciplinary graduate study and research groups, such as the Energy Research Laboratory at the Massachusetts Institute of Technology.

Others might develop strong

Shift in emphasis in Office of Energy Research support for basic energy sciences from 1975-81

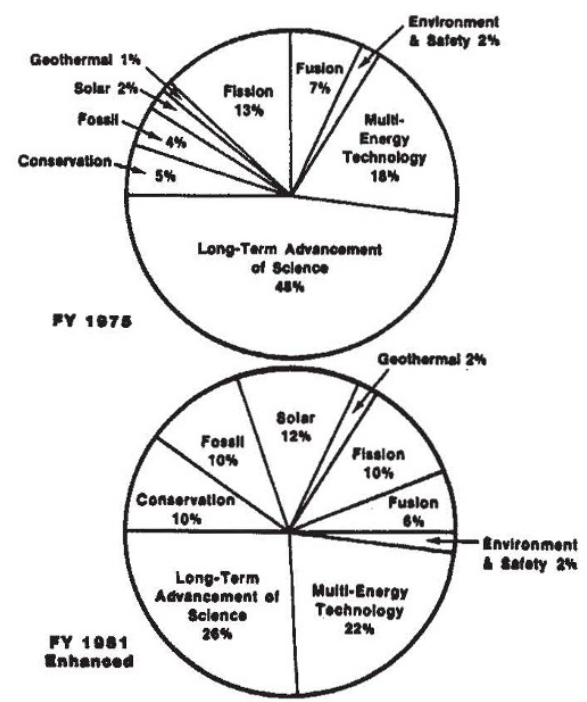

programmes applicable to a variety of energy technologies - such as research on high temperature chemistry applicable to nuclear, solar, fossil and geothermal technology - or involve research on the biomedical and social sciences related to energy supply and demand.

The proposal was speedily processed by the DoE, and submitted in late December to the Office of Management and Budget as a last minute addition to the 1981 budget request. OMB agreed to provide $\$ 3$ million for the scheme - expected to be enough to get four or five centres started - but insisted that further money would only be available if proposals are of a sufficiently high standard.

Dr Edward Frieman, director of the Office of Energy Research, told the Energy Research Advisory Board last week that proposals would have to demonstrate some special qualities, such as a strong interdisciplinary basis or close links with private industry, to qualify for funding.

"We do not want to see just a repackaging of our support for basic energy sciences", Dr Frieman said. "If the quality of the proposals is not high enough, I will not fund the programme".

Several major hurdles face the energy centres scheme, in addition to the scepticism of budget officials. One is the inevitable political infighting over where the first centres should be situated, given the traditional desire of Congressmen for 'equitable distribution' of federal dollars between geographical regions.

A second is the response of the national multipurpose laboratories supported by the DoE to a proposal that would seem to shift yet more research funding away from the laboratories into the university system. The department's budget proposal for 1981 is that the universities' share of OER funding should increase from $22 \%$ to $24 \%$, with a corresponding reduction in the proportion of support from the national laboratories (although the latter have been provided with $\$ 60.3$ million to improve basic facilities and their net funding will still increase).

Energy department officials, however, have currently taken as a key policy target the need to establish an adequate "technology base" for all its various energy-supply activities; and argue that, taking a leaf from the Defense Department's book and echoing the AAU, this can partly be achieved by emphasising goal-oriented basic enrolments research.

Universities, facing declining student enrolments and contracting research possibilities elsewhere, are keen to fit the bill. In the words of Dr Saxon: "A new programmatic departure ... will signal the deliberate mobilisation of scientific talent in universities for the assault on energy problems of all sorts."

David Dickson 